\title{
Modeling and Mapping Personal Learning Environment of Thai International Higher Education Students
}

\author{
Mohamed Ali Sharafuddin ${ }^{1} \nless$ \\ Buncha Panacharoen Sawad ${ }^{2}$ \\ Sarun Wongwai ${ }^{3}$
}

'Lecturer-Faculty of Business Administration, St. Theresa International College, Thailand Email:mohamed.tourism@gmail.com

Associate Professor, Faculty of Education, St. Theresa International College, Thailand

${ }^{3}$ Assistant Professor, Faculty of Education, St. Theresa International College, Thailand

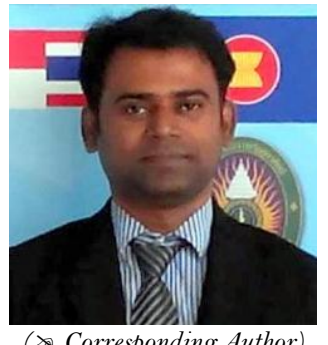

\section{Abstract}

This research article is part of a periodic study conducted to understand, model, map and to develop an integrated approach for effective and interactive self-learning phases of Thai International Hospitality and Tourism higher education students. Questionnaire containing both qualitative and quantitative questions was distributed at the beginning of the semester to understand the students' personal learning environment during their self-learning phases. After obtaining mutual agreement with the students, the researcher diffused the course related contents and assignments through observed personal learning environment and the changes that took place in it. Thereafter, the students' learning experience was measured again by the end of the semester with another quantitative questionnaire. Paired sample t-test and regression analysis were conducted to analyze the outcomes. The results revealed that there was statistically significant difference between the past and the present self-learning phases of personal learning environment on using micro blogging, academic material search engines, group chats, collaborative office suites (Social Networking Tools), Microsoft office suite and other traditional methods such as using teaching learning resources and infrastructure provided by institution (books, handouts, lecture notes and university library). The multiple linear regression results revealed that, the above mentioned self-learning phases of PLE attributes has significant and positive impact on overall learning experience.

Keywords: Tourism and hospitality education, Higher education, Self-Learning phases, Personal learning environment, Social networking tools.

Citation | Mohamed Ali Sharafuddin; Buncha Panacharoen Sawad; Sarun Wongwai (2018). Modeling and Mapping Personal Learning Environment of Thai International Higher Education Students. Asian Journal of Education and Training, 4(1): 35-40. History:

Received: 16 January 2018

Revised: 1 February 2018

Accepted: 5 February 2018

Published: 6 February 9018

Licensed: This work is licensed under a Creative Commons

Attribution 3.0 License (c))

Publisher: Asian Online Journal Publishing Group
Contribution/Acknowledgement: All authors contributed to the conception and design of the study.

Funding: This study received no specific financial support.

Competing Interests: The authors declare that they have no conflict of interests.

Transparency: The authors confirm that the manuscript is an honest, accurate, and transparent account of the study was reported; that no vital features of the study have been omitted; and that any discrepancies from the study as planned have been explained.

Ethical: This study follows all ethical practices during writing.

\section{Contents}

1. Introduction 36

2. Methodology 36

3. Analysis and Discussion................ 39

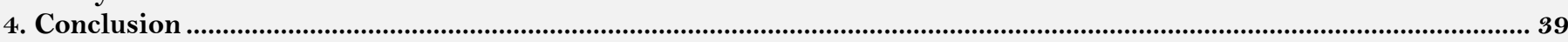

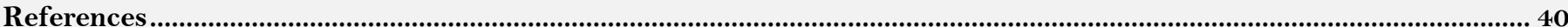




\section{Introduction}

Research on understanding the personal learning environment, its related use of technology and adopting various related approaches for offering better learning experience during Self learning phases of higher education, is gaining more focus in recent years. Different concepts regarding personal learning environment have evolved over time. Van Harmelen (2006) defined personal learning environment (PLE) as "a single user's e-learning system that provides access to a variety of learning resources, and that may provide access to learners and teachers who use other PLEs and/or VLEs". He also stated that control of PLEs may vest with the individual users. Whereas Attwell (2007) also mentioned that "Personal Learning Environments are not an application but rather new approach to the use of new technologies for learning. PLEs provide learners with their own spaces under their own control to develop and share their ideas. Moreover, PLEs can provide a more holistic learning environment, bringing together sources and contexts for learning hitherto separate. Students learn how to take responsibility for their own learning". Further, researches with specific focus on role of social networking in higher education are also gaining focus among distance learning and online course administrators. Wang (2010) explains the approach and its process saying that, "By obtaining information, producing insight, undertaking analysis and collaboration in the course of knowledge building and by way of an instructed learning process, these networks create all manners of interpersonal associations and learning opportunities." Santos et al. (2010) in their social network research analyzed the interactions established between the network actors during their workshop to understand the network development, learner's group formation, relationship patterns and communication flow between them. They stated that using technological tools in higher education has got its major advantage of easy access to resources among stakeholders of the learning environment and research on understanding the communication channels provides an opportunity to manage the higher education process. In general, PLE is seen more as a learner centric - technology enabled - socially networked - approach beyond the boundaries of traditional learning management system like which is usually institution centric and has more control over the students' learning styles and approaches. Also all researchers agree that, even though learners use common social networking tools and other traditional resources, personal learning environment might be unique. This research article focuses on two main objectives. First, this study endeavors to develop a model for understanding the personal learning environment perspectives of Thai international tourism and hospitality students and their use of technology during their self-learning phases, and map them accordingly. Secondly, to diffuse the course related contents and assignments through observed personal learning environment and measure the students learning experience.

\section{Methodology}

Since personal learning environment (PLE) is unique and this research focus on finding out the technology used by Thai international tourism and hospitality students to learn during their self-learning phases and to diffuse the course related contents and assignments through observed personal learning environment (O-PLE) and measure the students learning experience, the researcher adopted the grounded theory approach. The pilot study began with the collection of qualitative data from students by asking them how they overcome language and learning barriers to complete their assignments during their self-learning phases. Our previous study also revealed that, searching relevant information in various formats from internet and teaching each other through smart phone and social networks by giving feedbacks within themselves on their assignments during student's self-learning phases are the highly agreed activities (Tanyong and Sharafuddin, 2016). All of the students answered that they depend on multiple resources (both online and offline) to complete their assignments during their self-learning phases. The qualitative results of self-learning phases of the students' PLE were mapped based on students' answers and presented in Figure 1: Personal Learning Environment of self-learning phases. The map shows that the students were using search engines such as (Google, Yahoo, Bing and Ask) and academic material search engines (Base, Citeulike, Google Scholar and Slideshare) to search relevant information, watch videos (Youtube, Facebook, Yahoo, Vimeo, Metacafe and Instagram), search photos (Wikimedia Commons, Pin Interest and search engines), listen to audios (Imusic, Pandora and Soundcloud), use both online (Google forms, Google docs and Google calendar) and offline productivity suites ( MS Office), micro blog (Facebook, Soup, Tumblr, Google+ and Identi.Ca) to ask help from friends other than their classmates, group chat (Google+, Facebook, Line, Whatsapp, Wechat and Skype) along with their traditional resources ( books, lecture notes, handouts, running notes, and college library resources). With the above mentioned sources as variables, a quantitative questionnaire with 5-point Likert Scale that includes frequency of use as descriptors (1-Never, 2-Rarely, 3-Sometimes, 4-Very Often, and 5-Always) was developed and distributed at the beginning of the semester to understand the students' personal learning environment during their past self-learning phases. After obtaining mutual agreement with the students, the researcher diffused the course related contents and assignments through observed personal learning environment and the changes in personal learning environment and students learning experience was measured again by the end of the semester with another quantitative questionnaire (Needs paraphrasing coz this has been used in the abstract). Paired sample t-test and regression analysis was conducted to analyze the outcomes. 


\section{Personal Learning Environment of Self Learning Phases}

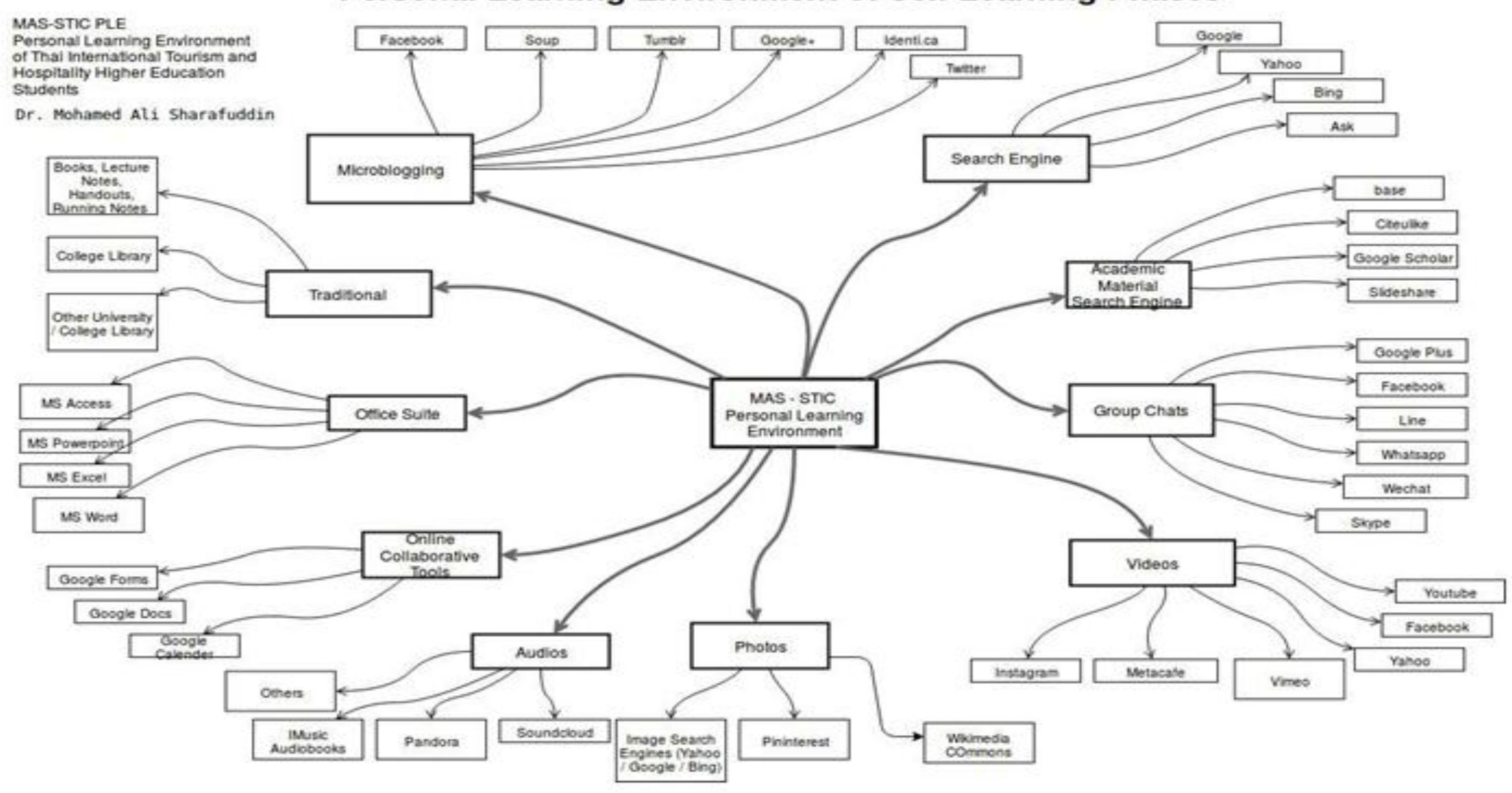


Asian Journal of Education and Training, 2017, 4(1): 35-40

Table-1. Paired Sample T-Test of Past and Present PLE

\begin{tabular}{|c|c|c|c|c|c|c|c|c|c|c|c|}
\hline \multirow[t]{2}{*}{ Variables } & \multicolumn{3}{|l|}{ Past } & \multicolumn{3}{|c|}{ Present } & \multirow[t]{2}{*}{$\mathbf{N}$} & \multirow[t]{2}{*}{ Mean Difference } & \multirow[t]{2}{*}{$T$} & \multirow[t]{2}{*}{ Df } & \multirow[t]{2}{*}{ P-Value } \\
\hline & Mean & S.D. & S.E. & Mean & S.D. & S.E. & & & & & \\
\hline Micro blogging & 2.492 & 0.72 & 0.07 & 2.686 & 0.67 & 0.06 & 111 & -0.194 & -3.38 & 110 & $<.001$ \\
\hline Search Engine & 2.687 & 0.68 & 0.06 & 2.511 & 0.62 & 0.06 & 111 & 0.176 & 2.287 & 110 & 0.998 \\
\hline Academic Material Search & 2.258 & 0.93 & 0.09 & 2.934 & 0.78 & 0.07 & 111 & -0.675 & -6.23 & 110 & $<.001$ \\
\hline Group chats & 3.212 & 0.66 & 0.06 & 3.572 & 0.5 & 0.05 & 111 & -0.36 & -5.29 & 110 & $<<.001$ \\
\hline Learn through online videos & 2.751 & 0.57 & 0.05 & 2.807 & 0.58 & 0.06 & 111 & -0.056 & -1.12 & 110 & 0.132 \\
\hline Image search & 2.682 & 0.75 & 0.07 & 2.671 & 0.73 & 0.07 & 111 & 0.011 & 0.185 & 110 & 0.573 \\
\hline Audio search & 2.359 & 1.03 & 0.1 & 2.144 & 1.12 & 0.11 & 111 & 0.209 & 2.124 & 110 & 0.982 \\
\hline Collaborative tools & 2.565 & 1.04 & 0.1 & 3.414 & 0.76 & 0.07 & 111 & -0.849 & -8.15 & 110 & $<.001$ \\
\hline Office suite & 3.225 & 0.89 & 0.08 & 3.291 & 0.84 & 0.08 & 111 & -0.066 & -1.91 & 110 & 0.029 \\
\hline Traditional methods & 3.559 & 0.79 & 0.08 & 3.769 & 0.61 & 0.06 & 111 & -0.21 & -2.67 & 110 & 0.004 \\
\hline
\end{tabular}

Source: Calculated from primary data 


\section{Analysis and Discussion}

\subsection{Paired Sample T-Test}

Paired Sample T-Test was performed to test the mean difference between the self-learning phases of the PLE of hospitality and tourism students in the past and the present scenario. The paired sample T-Test in Table 1 revealed the mean differences between the past and present self-learning phases in PLE. The results indicate that there is a statistically significant difference in the mean scores and positive growth in the use of micro-blogging [past $(\mathrm{M}=2.42$, S.D.=0.719) and present $(\mathrm{M}=2.686$, S.D.=0.063) with a $\mathrm{t}(110)=-3.384, \mathrm{p}<0.05$. , academic material search [past $(\mathrm{M}=2.258, \mathrm{~S} . \mathrm{D} .=0.929)$ and present $(\mathrm{M}=2.934$, S.D. $=0.776)$ with a $t(110)=-6.226, \mathrm{p}<0.05$.$] ,$ group chats [past $(\mathrm{M}=3.212$, S.D.=0.663) and present $(\mathrm{M}=3.572$, S.D.=0.495) with a $t(110)=-5.293, \mathrm{p}<0.05 . \overline{\text {, }}$, Collaborative tools $[(\mathrm{M}=2.565, \mathrm{~S} . \mathrm{D} .=1.039)$ and present $(\mathrm{M}=3.414, \mathrm{~S} . \mathrm{D} .=0.761)$ with a $t(110)=-8.154, \mathrm{p}<0.05$.$] ,$ office suite [past $(\mathrm{M}=3.225, \mathrm{~S} . \mathrm{D} .=0.888)$ and present $(\mathrm{M}=3.291, \mathrm{~S} . \mathrm{D} .=0.837)$ with a $t(110)=-1.908, \mathrm{p}<0.05$.$] and$ traditional methods [past $(\mathrm{M}=3.559$, S.D.=0.794) and present $(\mathrm{M}=3.769$, S.D.=0.605) with a $t(110)=-2.665$, $\mathrm{p}<0.05$.$] . Whereas, there is no significant difference in 'learning through watching online videos', 'image search'$ and 'audio search'. The result also indicates that the use of search engine has been decreased in the present scenario. Overall, after dissemination of the course related contents and assignments through observed personal learning environment (O-PLE) the personal learning environment of student's self-learning phases (SLP-PLE) became more interactive than their past PLE (P-PLE). Hence it is concluded that diffusing course related contents through observed personal learning environment (O-PLE) can make the personal learning environment of student's self-learning phases (SLP-PLE) more interactive and increase students participation. Further linear regression was conducted to evaluate the impact of present attributes of self-learning phases of (SLP-PLE) on overall learning experience.

\subsection{Linear Regression}

This study hypothesized that there is a significant impact of present attributes of self-learning phases of PLE on overall learning experience of the students.

Table-2. Linear Regression Analysis

\begin{tabular}{|c|c|c|c|c|c|c|}
\hline Model & Variables & $\mathbf{B}$ & Standard Error & $\boldsymbol{\beta}$ & t-value & p-value \\
\hline \multirow{7}{*}{1} & Present Micro blogging & 0.137 & 0.045 & 0.219 & 3.062 & 0.003 \\
\hline & Present search engine & -0.04 & 0.054 & -0.06 & -0.7 & 0.487 \\
\hline & Present Group Chats & 0.051 & 0.051 & 0.061 & 1 & 0.32 \\
\hline & Present traditional methods & 0.101 & 0.042 & 0.147 & 2.422 & 0.017 \\
\hline & Present videos & 0.09 & 0.058 & 0.124 & 1.549 & 0.125 \\
\hline & Present Photos & 0.1 & 0.045 & 0.175 & 2.212 & 0.029 \\
\hline & Present audio & 0.088 & 0.028 & 0.237 & 3.115 & 0.002 \\
\hline
\end{tabular}

The multiple linear regression results revealed the significant impact of students present self-learning phases of PLE on Overall satisfaction. The results shows the regression equation $\mathrm{F}(10,100)=20.74, \mathrm{p}<0.01$. The multiple correlation coefficient $\mathrm{R}$ was at 0.821 with an $\mathrm{R}$ square value of 0.675 , which indicates that the attributes of self-learning phases of PLE accounted for $67.5 \%$ variation on the dependent variable (DV) overall learning experience. The result indicates that micro blogging $(\mathrm{b}=0.219, \mathrm{p}<0.05)$, academic material search engine $(\mathrm{b}=0.267, \mathrm{p}<0.05)$, collaborative tools $(\mathrm{b}=0.158, \mathrm{p}<0.05)$, office suite $(\mathrm{b}=0.164, \mathrm{p}<0.05)$, traditional methods $(b=0.147, p<0.05)$, photos $(b=0.175, p<0.05)$, audio $(b=0.237, p<0.05)$ have significant and positive impact on overall learning experience; whereas the variables Group chats $(b=0.061, p>0.05)$, videos $(b=0.124, p>0.05)$ is non-significant and the variable search engine $(b=-0.056, p>0.05$, non-significant) has negative impact on overall learning experience. However, the major important attributes of self-learning phases of PLE has significant and positive impact on overall learning experience.

The regression equation could be written as predictive of overall learning experience $=0.467-0.038$ (Search Engine) +0.137 (Micro blogging) +0.143 (Academic material search engine) +0.051 (Group chats) +0.086 $($ Collaborative tools $)+0.082$ (Office suite $)+0.101$ (Traditional methods) +0.090 (Videos) $+0.100($ Photos $)+$ o.088 (Audio).

The results of the study confirmed that:

1. Diffusing course related contents through observed personal learning environment (O-PLE) can make the personal learning environment of student's self-learning phases (SLP-PLE) more interactive and increase students' participation.

2. The overall learning experience can be improved by diffusing the course related self-learning contents through various interactive tools.

\section{Conclusion}

The study proves that the students Self-Learning Phases of Personal Learning Environment (SLP-PLE) has been improved in the present scenario compared to their past. There is a significant impact of studies attributed to SLP-PLE on students' overall learning experience. Hence, lecturers must focus on diffusing course related contents through observed personal learning environment (O-PLE) to make the personal learning environment of student's self-learning phases (SLP-PLE) more interactive which eventually result in increased students course participation and have a positive impact on overall students learning experience. Focusing only on international tourism and 
hospitality higher education students is the major limitation of this study. Further studies covering students of other major courses would reveal more results on effectiveness of observed personal learning environment (O-PLE) on students learning experience.

\section{References}

Attwell, G., 2007. Personal learning environments-the future of elearning? E-Learning Papers, 2(1): 1-8. View at Google Scholar

Santos, F.L., Q.D.A. de Cima, J. Paz and P. Fidalgo, 2010. Building proactive teachers: A workshop to provide for self-regulated learning experiences in teacher education. In Self-regulated Learning in Technology Enhanced Learning Environments: Problems and Promises, Proceedings of the STELLAR -TACONET Conference, pp. 31-39. Retrieved from: http://www.itd.cnr.it/download/OBarcelona\%20proceedings\%20fourth\%20taconet\%20conference.pdf\#page $=45$.

Tanyong, S. and M.A. Sharafuddin, 2016. Understanding personal learning environment perspectives of Thai international tourism and hospitality higher education students. Journal of Education and Practice, 7(10): 128-139. View at Google Scholar

Van Harmelen, M., 2006. Personal learning environments. Advanced Learning Technologies, 2006. Sixth International Conference on. IEEE. pp: 815-816.

Wang, L., 2010. How social network position relates to knowledge building in online learning communities. Frontiers of Education in China, 5(1): 4-25. View at Google Scholar | View at Publisher 